\title{
Epidemiology of valvular heart diseases in Africa
}

\section{Vuyisile T. Nkomo}

Assistant Professor of Medicine, Division of Cardiovascular Diseases and Internal Medicine, Mayo Clinic, Rochester, Minnesota

Address for correspondence:

Vuyisile T. Nkomo

Division of Cardiovascular Diseases and Internal Medicine

Mayo Clinic

Rochester, Minnesota

55905

Email:

nkomo.vuyisile@mayo.edu

\section{INTRODUCTION}

One of the earliest cases, if not the first case, of rheumatic fever (RF) with rheumatic heart disease (RHD) reported in Africa was reported by medical officers Procter and Hargreaves in 1932 in the East African Medical Journal.(I) One of the medical officers had been engaged in native practice ${ }^{(1)}$ for eleven years while the other had examined a large number of African school children and neither had found a case of RF or RHD prior. The reported case was that of a 25 year old male from Lumbwa, Kenya admitted to a local hospital with two months duration of painful and swollen joints and a fever. On physical examination, both a systolic and a diastolic murmur were heard consistent with leftsided valvular regurgitation. Infective endocarditis was ruled out since the patient's condition improved with bed rest and salicylates. He was dismissed after about a week of admission and was advised to seek follow up upon discharge.(I) In the 76 years since that case report, RF and RHD have become a major but under-appreciated public health problem in Africa where they account for significant cardiac morbidity and mortality in a substantial number of children and young adults. ${ }^{(2-7)}$

\section{ABSTRACT}

Rheumatic heart disease (RHD) resulting from rheumatic fever (RF) is the main form of valve disease in Africa. Other forms of valve diseases such as myxomatous mitral valve disease, age-related valve disease, sub-valvular aneurysms or valve disease related to endomyocardial fibrosis are less common than RHD. In developed countries, RF and RHD are rare and no longer pose a public health problem, but the combination of poverty, lack of awareness, lack of infrastructure and resources, and social instability contribute to the persistence of RF and RHD in Africa. The presence of other major infectious diseases also shifts attention away from RF and RHD. Contemporary population-based epidemiologic data utilising echocardiography to detect valve disease suggests the prevalence of valve diseases in Africa is likely much higher than previously thought, meaning the estimated mortality, morbidity and socio-economic burden they cause could also be much higher than currently appreciated. Increased efforts are needed to define the scope of the problem of valve diseases in Africa to draw attention to these illnesses and step up public health efforts to control and eradicate them as has already been achieved in other parts of the world. This article highlights the public health problem of valve diseases in Africa, the efforts underway to combat them and the attendant challenges.

SAHeart 2009; 6:12-18

\section{ETIOLOGY OF RHEUMATIC FEVER}

The current understanding of the pathogenesis RF is that RF is the result of a delayed immune response to Group A B-haemolytic streptococcus (GABHS) pharyngitis after a latent period ranging from 1-5 weeks. ${ }^{(8)}$ Our understanding of this current working paradigm is based on epidemiologic and experimental data largely from the United States ${ }^{(9,10)}$ more than half a century ago when RF and RHD were still a major public health problem there. Rheumatic fever rarely affects adults and occurs mainly in children in the age group $5-15$ years. ${ }^{(11,12)}$ About 3\% of GABHS pharyngitis cases will develop RF of left untreated, but the risk of RF increases substantially to about $75 \%$ with a recurrent episode of GABHS pharyngitis. ${ }^{(13-15)}$ The precise pathogenic mechanism of RF has not been fully defined. ${ }^{(2)}$ 
Intriguing data from Australian aborigines affected by high incidence of RF suggests GABHS pyoderma or even nonGABHS may be responsible for RF and RHD in that population. ${ }^{(16)}$ However, similar data from other high incidence populations does not exist. ${ }^{(17)}$

\section{SEQUELAE OF RHEUMATIC FEVER AND}

\section{RHEUMATIC HEART DISEASE}

Rheumatic fever affects multiple organs, and the clinical presentation is variable depending on multiple factors including the organs affected, severity of involvement and the time of presentation. ${ }^{(18)}$ The diagnosis of RF is based on the 2002-2003 World Health Organisation $(\mathrm{WHO})$ revised Jones criteria. ${ }^{(2,19)}$

Cardiac involvement in RF may be pancarditis, and it is cardiac involvement in the form of valvulitis that is the most important cause of morbidity and mortality. ${ }^{(20)}$ There is evidence of cardiac involvement during the acute episode in 40 to $80 \%$ of cases of acute RF2I, (21-23) but cardiac involvement almost always occurs in recurrent episodes of RF.(24) $A$ large majority of those who have carditis during RF episodes will develop progressive RHD from inflammation and scarring of the heart valves, typically left-sided, which may result in significant valvular regurgitation and or stenosis and heart failure in childhood or early adulthood.(25) Determinants of the outcome of RHD are the age of first attack of RF and the frequency and severity of recurrent attacks.(26) Cardiac involvement in the attack of RF may range from mild to severe and should be suspected on clinical grounds when a murmur (systolic or diastolic) is heard on physical examination or if there is presence of cardiomegaly or unexplained heart failure. ${ }^{(18)}$

Hospital-based studies and cause of death studies across Africa are all consistent and show that RHD is the main cause of cardiac morbidity and mortality in children and young adults, ${ }^{(4)}$ with heart failure being the predominant cause of morbidity and mortality, followed by other complications such as native valve infective endocarditis, systemic embolisation, pulmonary hypertension, atrial arrhythmias, or complications related to valve surgery. ${ }^{(26-32)}$

The leading cause of heart failure in the forms of RHD typically seen in Africa affecting young individuals in their first or second decades is valve regurgitation mainly of the mitral and aortic valves. ${ }^{(26,28)}$ It is common clinical course for RF and RHD to result in death in these young individuals ${ }^{(28)}$ and the reasons for this malignant course are not entirely clear, but may partly be related to recurrent episodes of RF with inadequate secondary prophylaxis and multivalvular involvement. ${ }^{(28)}$ Delayed clinical presentation also contributes to high morbidity and mortality. ${ }^{(32)}$

The mechanism of mitral valve regurgitation is related to inflammation of the mitral valve apparatus leading to dilatation of the mitral anulus and elongation of the chordae and leaflets which results in prolapse of the anterior mitral leaflet. ${ }^{(26,33)}$ Aortic valve regurgitation, and less commonly tricuspid valve and pulmonary valve regurgitation are also related to inflammation of the valve leaflets and anuli.(34) The presence of mixed valve regurgitation and stenosis or pure valve stenosis is more common in older individuals with chronic and less active rheumatic carditis. ${ }^{(26,34)}$

Infective endocarditis is a devastating sequelae of RHD where RHD accounts for up to $76.6 \%$ of the underlying predisposing condition in some studies. ${ }^{(35)}$ Again, those affected by infective endocarditis are typically young where morbidity and mortality are high due largely to new or worsening heart failure or neurologic complications. ${ }^{(27,35,36)}$ In the 3-year prospective epidemiology study of infective endocarditis, Koegelenberg and colleagues found a six month mortality of $35.6 \%$. $^{(35)}$

Rheumatic valve diseases, namely mitral valve stenosis with or without regurgitation, is the most common underlying cardiac condition complicating pregnancies in young women in Africa ${ }^{(37,38)}$ with a maternal mortality rate of up to $9.5 \%{ }^{(39)}$ It is not unusual for the diagnosis of RHD to be made for the first time late during pregnancy ${ }^{(40)}$ and the attendant consequences of late diagnosis are serious for both mother and child(40,41) Nqayana and colleagues recently published a retrospective review of all patients admitted with cardiac disease in pregnancy over a I-year period at their tertiary hospital. ${ }^{(42)}$ RHD (mitral valve disease) was the commonest aetiology of cardiac disease in the 95 patients included with the majority aged 21-25 years. There was high maternal morbidity with 13 patients admitted in cardiac failure, 9 with atrial fibrillation, 3 required intensive-care management, 8 required balloon mitral valvuloplasty and I underwent valve replacement at 32 weeks' gestation. ${ }^{(42)}$ There were adverse fetal outcomes with 
86 live births of the 97 deliveries due largely to problems with anticoagulation. ${ }^{(42)}$

\section{INCIDENCE AND PREVALENCE OF RF AND RHD IN AFRICA}

The number of new cases of RF per 100000 per year in Tunisia was 30 in 1990 and in Algeria II, I in 1997 and 6.2 in 2000.(43,44) There are no reliable data on the number of new cases of RF per year in sub-Saharan Africa ${ }^{(45)}$ and the estimated 13 per 100000 per year is based on incidence rates from the Middle East and North Africa. ${ }^{(43)}$ Identifying new cases of RF demands active surveillance systems which requires enough skilled manpower and other resources such as laboratories which do not exist in many parts of Africa. ${ }^{(2)}$ The World Health Organisation (WHO) has however demonstrated previously that setting up such surveillance systems is feasible in Africa, but that such systems falter operationally over time. ${ }^{(46)}$

The $\mathrm{WHO}$ estimated that there were 12 million people worldwide in 1994 with RF and RHD, the majority of them in developing countries.(2) An update of the worldwide burden of RF and RHD estimated that 15.6-19.6 million people were affected by RHD with 2.4 million of those being children in the age group 5-14 years. $^{(4,43)}$ Forty-two percent of the estimated 2.4 million children affected by RHD are located in sub-Saharan Africa. The number of people with previous RF who need secondary prophylaxis was estimated to be 1.88 million and the estimated number of deaths per year from RHD based on an annual mortality of $1.5 \%$ per year was $233364-294398 .^{(4)}$

The prevalence of RHD in the update was estimated to be highest in sub-Saharan Africa with a prevalence of 5.7 per I 000 , compared to 1.8 per I 000 in North Africa, 2.2 per I 000 in South central Asia and $0.3 \%$ in developed countries. ${ }^{(4)}$ These estimates were based on large population-based data from the 1980s and 1990s where school age children were screened for RHD by clinical examination confirmed by echocardiographic and Doppler studies in some studies. $(4,47,48)$

Previous studies in school children on prevalence of RHD utilising clinical screening plus or minus echocardiography show variation in the prevalence of RHD from region to region within Africa ${ }^{(4)}$ ranging from 1.0 per 1000 in Inanda, South Africa to as high as 14.0 per | 000 in Kinshasa, Democratic Republic of Congo and I4.6 per I 000 Lusaka, Zambia. ${ }^{(6,43)}$ These studies have also shown that the prevalence of RHD is higher in poorer communities as demonstrated by the study in Addis Ababa, Ethiopia where the prevalence of RHD was 1.0 per I 000 in children of high socioeconomic status compared to 7.1 per 1000 in those of low socio-economic status. ${ }^{(49)}$

A seminal epidemiologic study on the prevalence of RHD in Africa in school children was recently conducted and was published by Marijon and colleagues in the New England Journal of Medicine in 2007. (7) The study was conducted from May through October 2005 where 2170 children age 6 to 17 years were randomly selected from six public primary schools among the I | 40000 children living in the capital city Maputo in Mozambique.(7) All children underwent a detailed clinical examination performed by physicians experienced in the diagnosis of murmurs and RHD and all children underwent a detailed echocardiographic examination. ${ }^{(7)}$ Only left-sided valves were assessed for features of RHD. Echocardiographic criteria for RHD were the presence of any definite evidence of mitral or aortic regurgitation in two planes accompanied by at least two of the following morphologic abnormalities: restricted leaflet mobility, focal or generalised valve thickening, and abnormal subvalvular thickening.(7) Children who were found to have an organic murmur by clinical examination and RHD was confirmed by echocardiography were classified as having clinically detected RHD. (7)

The findings of the study were striking with respect to both the overall prevalence of RHD found in the children as well as the gross underestimation of RHD prevalence by clinical examination alone. Out of 2170 children enrolled, 3 had a prior history of acute RF, I had known RHD, and only 2 were found to have acute RF.(7) The number of cases of RHD detected by clinical examination alone was 5 (2.3 per I 000 children), and by echocardiographic examination 66 (30.4 per I 000), and by echocardio graphic examination but not clinical examination 61 (28.1 per I 000). ${ }^{(7)}$ Therefore, $92.4 \%$ of the cases of rheumatic valve diseases were clinically silent and occurred in children who were asymptomatic without an audible murmur. ${ }^{(7)}$ By extension, of the I 140000 children age 6- 17 years in Maputo, an estimated 2622 cases of RHD would be detected by clinical screening compared to 34656 cases by echocardiographic screening. ${ }^{(7)}$ 


\section{ECHOCARDIOGRAPHIC SCREENING OF}

\section{VALVE DISEASE}

Echocardiographic directed screening of valve diseases will undoubtedly uncover substantially higher prevalence of RHD across the continent. The geographic distribution will likely be similar to what has been documented, namely that the burden of disease will be highest in poorer countries and communities.

Subclinical valve diseases in all stages of RF is not uncommon ${ }^{(50-52)}$ and is not necessarily transient as demonstrated by Figueoa and colleagues in Chile, South America, in a long-term prospective follow up study of patients with subclinical rheumatic valvulitis. ${ }^{(53)}$ Although there is a lack of data in Africa documenting the incidence of echocardiographically detected subclinical disease in cases of acute RF, the study by Marijon and colleagues in Mozambique sheds light on what appears to be an enormous problem of subclinical valve disease.(7) The argument against the standard use of echocardiography to detect valve diseases in Africa centers around cost, lack of equipment and echocardiographic expertise, and potential over diagnosis of valve disease when physiologic regurgitation is found.(2) However, the counter argument for the use of echocardiographic screening and diagnosing of RHD in high prevalent settings is being correctly advanced by some. ${ }^{(2,17,53,54)}$ Echocardiography is superior to physical examination in diagnosing valve disease and it makes sense to try to find models and establish guidelines for proper application of echocardiography for the sake of determining true incidence and prevalence of disease and to identify cases needing secondary prophylaxis. ${ }^{(7,17)}$

\section{PREVENTION AND MANAGEMENT OF}

\section{VALVE DISEASES}

The prevention and control of RF and RHD in Africa is now a priority. The Pan African Society of Cardiology (PASCAR) convened a workshop in 2005 to frame a road map and action plan for the prevention and elimination of RF and RHD in Africa during this lifetime. ${ }^{(5,55)}$ The action plan adopted at the workshop was called the Awareness Surveillance Advocacy Prevention (ASAP) Programme ${ }^{(56)}$ which aims to $(1)$ raise general awareness about RF and RHD (2) establish surveillance systems for the detection and treatment of cases of RF and RHD (3) champion advocacy for RF and RHD and (4) implement proven primary and secondary prevention strategies.

The road to achieving the goal of eradicating RF and RHD has obvious barriers. ${ }^{(56)}$ There is widespread lack of awareness about the causes, symptoms, risks and other problems associated with RF and RHD. (56) Part of this may be related to coexistent high rates of other public health problems such as HIVIAIDS, malaria, and tuberculosis which shift attention away from RF and RHD(17,56) However, even those affected by RF and RHD often do not receive adequate education or do not understand much of what they are told about the illness. ${ }^{(57)}$ Setting up surveillance systems to capture new cases and regularly follow identified cases requires concerted coordinated effort by an aware, dedicated and well supported health care system with laboratory capabilities. ${ }^{(2)}$ Advocacy for RF and RHD faded largely due to the virtual disappearance of these diseases in developed nations and the lack of reliable epidemiologic data in Africa and other developing countries that highlight RF and RHD as major public health problems. ${ }^{(17,56)}$

Primary prevention requires timely treatment of suspected or confirmed GABHS to prevent RF, but laboratory confirmation of GABHS remains the gold standard and these laboratory capabilities are not readily available.(2) Rapid diagnostic kits are helpful, but cannot substitute for a laboratory and a negative kit result requires laboratory confirmation. ${ }^{(58)}$ It is recommended that in communities where RF is endemic, all cases of sore throat in children 3- 15 years old be treated as GABHS pharyngitis unless there is ulceration, or hoarseness, or watery nasal congestion, and/or conjunctivitis which argue against GABHS pharyngitis. ${ }^{(59)}$ The WHO Acute Respiratory Infection Guideline lacks sensitivity for the diagnosis of GABHS pharyngitis since it requires both pharyngeal exudate and tender, enlarged lymph nodes to make the diagnosis. ${ }^{(60)}$ Complicating primary prevention strategies is the absence of symptoms of pharyngitis in a significant proportion of those who develop RF.(61)

Secondary prevention is the long-term administration of penicillin after the first episode of RF to prevent recurrence and duration of treatment is tailored to the presence and severity of valve disease according to the $\mathrm{WHO}$ recommendations. ${ }^{(2.59)}$ Secondary prevention is the strategy so far proven most cost effective in 
the control of RF and RHD and is the main strategy supported by the $\mathrm{WHO}^{(2)}$ This strategy requires identification of cases and establishment of registries of patients to ensure continued coordinated administration of antibiotics every 3-4 weeks.(2) However, whether administration of secondary prevention for all children with echocardiographically detected subclinical valve disease is warranted has not been shown. ${ }^{(54)}$

Valve surgery is the way to managed valve disease causing heart failure, unless the risk is deemed to high. The difficulties associated with valve surgery in Africa are immediately apparent. The majority of the patients needing valve surgery are young and poor and availability of surgical resources and expertise is not widespread. (62) Tissue prosthesis are not durable in young patients ${ }^{(63)}$ and mechanical prosthesis are complicated by inadequate anticoagulation due to difficulties with follow up, thromboembolic events, hemorrhage, or infective endocarditis. ${ }^{(64)}$ Mitral valve repair is preferable to mitral valve replacement and is feasible in a number of patients, but there is risk of needing reoperation, particularly if valve repair is performed in the presence of active rheumatic carditis. ${ }^{(65)}$ Cardiopulmonary bypass during pregnancy is associated with high fetal loss.(66) Mitral valve replacement during pregnancy, if deemed the only option, should be delayed until after delivery whenever possible. ${ }^{(66,67)}$

Options for management of symptomatic mitral stenosis refractory to medical therapy and particularly complicating pregnancy include percutaneous balloon valvotomy or closed mitral commissurotomy. ${ }^{(67-69)}$ Mitral balloon valvotomy is preferred for severe mitral stenosis with pliable leaflets and without heavy commissural calcification, ${ }^{(68)}$ but closed mitral commissurotomy, which can be performed without need for cardiopulmonary bypass, remains a viable options when balloon valvotomy cannot be performed. ${ }^{(69)}$

\section{NON-RHEUMATIC VALVE DISEASE}

Other forms of valve disease previously reported in Africa include myxomatous mitral valve disease, age-related valve disease, subvalvular aneurysms, and valve disease related to endomyocardial fibrosis. Myxomatous mitral valve disease was first described in South Africa by Barlow and Bosman in 1966(70) and is characterised by variable myxomatous degeneration of the mitral valve leaflets and chordae associated with mitral leaflet prolapse or flail leaflets and mitral regurgitation. Myxomatous mitral valve disease is the leading indication for mitral valve surgery in developed countries, ${ }^{(71)}$ but is an uncommon indication for mitral valve surgery in surgical series reported from Africa. ${ }^{(6)}$ Valve diseases related to aging are the most common form of valve diseases in developed countries, ${ }^{(72)}$ and are also encountered in the elderly in Africa. ${ }^{(73)}$ However, age-related valve diseases of clinical significance were not part of the spectrum of heart disease and risk factors in a recent cohort study of a large black urban population in Soweto, South Africa. ${ }^{(74)}$ Congenital subvalvular aneurysms are rare and were also first described in Africa. ${ }^{(75,76)}$ These aneurysm may be located below the mitral or aortic valve and be associated with regurgitation, systemic embolisation, or rupture and are thought to be related to congenital weakness between the muscular ventricular wall and fibrous skeleton of the valve annulus. ${ }^{(77)}$ The cause of endomyocardial fibrosis is not well understood, but it is the most common cause of restrictive cardiomyopathy worldwide caused by deposition of fibrous tissue on endocardial surfaces causing heart failure associated with atrioventricular valve regurgitation. ${ }^{(78,79)}$ There is no medical therapy for this illness and surgical results of advanced disease are poor. (79) Mocumbi and colleagues recently performed a large transthoracic echocardiographic survey in a rural area of Mozambique and found a high prevalence of endomyocardial fibrosis of $19.8 \%{ }^{(79)}$ Most of those affected had mild-to-moderate abnormalities and it is hoped that early detection of disease with echocardiography will help in the study of the pathogenesis and in the development of new management strategies of this common disease. ${ }^{(79)}$

\section{CONCLUSION}

Valve diseases are common and are a serious public health problem in Africa. Recent epidemiologic data suggests the prevalence of valve disease is underestimated. More epidemiologic data utilising echocardiographic detection of valve disease is needed to define the full extent of the problem. The bulk of valve diseases are preventable and controllable through primary and secondary prevention measures, but these have not been implemented fully in Africa. PASCAR has appropriately created a sense of urgency in the efforts to eradicate RF and RHD and their efforts should be supported fully. 
I. Procter RAW, GHargreaves GM. A case of rheumatic fever in a Lumbwa native. The East African Medical Journal. 1932;9:332.

2. Anonymous. Rheumatic fever and rheumatic heart disease. World Health Organisation Technical Report Series. 2004;923:1 - 122.

3. Essop MR, Nkomo VT. Rheumatic and non-rheumatic valvular heart disease: epidemiology, management, and prevention in Africa. Circulation. 2005; I $12(23): 3584-359$ |.

4. Carapetis JR, Steer AC, Mulholland EK, et al. The global burden of group A streptococcal diseases. Lancet Infect Dis. 2005;5(I I):685-694.

5. Mayosi B, Robertson K, Volmink J, et al. The Drakensberg declaration on the control of rheumatic fever and rheumatic heart disease in Africa. S Afr Med J. 2006;96(3 Pt 2):246.

6. Nkomo VT. Epidemiology and prevention of valvular heart diseases and infective endocarditis in Africa. Heart. 2007;93(12):1510-1519.

7. Marijon E, Ou P, Celermajer DS, et al. Prevalence of rheumatic heart disease detected by echocardiographic screening. N Engl J Med. 2007;357(5):470-476.

8. Collis WRF. Acute rheumatism and hemolytic streptococci. Lancet. 1931;1: |34|-1345.

9. Denny FW, Wannamaker LW, Brink WR, et al. Prevention of rheumatic fever: Treatment of the preceding streptococcal infection. JAMA. 1950; 143:151-153.

10. Kaplan EL, Anthony BF, Chapman SS, et al. The influence of the site of infection on the immune response to group A streptococci. Journal of Clinical Investigation. 1970;49(7): 1 405-14 |4.

I1. Ben-Dov I, Berry E. Acute rheumatic fever in adults over the age of 45 years: an analysis of 23 patients together with a review of the literature. Semin Arthritis Rheum. 1980; 10(2): 100- 110.

12. Brundage JF, Gunzenhauser JD, Longfield JN, et al. Epidemiology and control of acute respiratory diseases with emphasis on group A beta-hemolytic streptococcus: a decade of U.S. Army experience. Pediatrics. 1996;97(6 Pt 2): 964-970.

13. Rammelkamp CH. Rheumatic heart disease: a challenge. Circulation. 1958; 17:842-851.

14. Wood HF, Stollerman GH, Feinstein AR, et al. A controlled study of three methods of prophylaxis against streptococcal infection in a population of rheumatic children. New England Journal of Medicine. 1957;257:394-398.

15. Taranta A, Wood HF, Feinstein AR, et al. Rheumatic fever in children and adolescents. IV. Relation of rheumatic fever recurrence rate per streptococcal infection to the titres of streptococcal antibodies. Annals of Internal Medicine. 1964:60(Suppl 5):47-57.

16. McDonald M, Currie BJ, Carapetis JR. Acute rheumatic fever: a chink in the chain that links the heart to the throat? The Lancet Infectious Diseases. 2004;4(4):240-245.

17. Carapetis JR. Rheumatic heart disease in developing countries. N Engl J Med. 2007;357(5):439-441.

18. Jones TD. The diagnosis of rheumatic fever. JAMA. 1944; | 26:48|-484.

19. Carapetis JR, McDonald M, Wilson NJ. Acute rheumatic fever. Lancet. 2005;366(9480): 155-168.

20. Feinstein AR, DiMasa R. Prognostic significance of valvular involvement in acute rheumatic fever. New England Journal of Medicine. 1959;260: I331-1 333.

21. Land MA, Bisno AL. Acute rheumatic fever. A vanishing disease in suburbia. JAMA. 1983;249(7):895-898.

22. Markowitz M. Observations on the epidemiology and preventability of rheumatic fever in developing countries. Clinical Therapeutics. 1981;4(4):240-25।.
23. Fraser GE. A review of the epidemiology and prevention of rheumatic heart disease: Part II. Features and epidemiology of streptococci. Cardiovascular Review and Report. 1996; 17(4):7-23.

24. Feinstein AR, Stern EK. Clinical effects of recurrent attacks of acute rheumatic fever: a prospective epidemiologic study of 105 episodes. Journal of Chronic Diseases. 1967;20(1):13-27.

25. Anonymous. Guidelines for the diagnosis of rheumatic fever. Jones Criteria, 1992 update. Special writing group of the committee on rheumatic fever, endocarditis, and Kawasaki disease of the council on cardiovascular disease in the young of the American Heart Association.[see comment][erratum appears in JAMA 1993 Jan 27;269(4):476]. JAMA. 1992;268(I5):2069-2073.

26. Marcus RH, Sareli P, Pocock WA, et al. The spectrum of severe rheumatic mitral valve disease in a developing country. Correlations among clinical presentation, surgical pathologic findings, and hemodynamic sequelae. Ann Intern Med. 1994; 120(3): 177-183.

27. Ifere OA, Masokano KA. Infective endocarditis in children in the Guinea savannah of Nigeria. Annals of Tropical Paediatrics. 1991; I (3):233-240.

28. Oli K, Asmera J. Rheumatic heart disease in Ethiopia: could it be more malignant? Ethiop Med J. 2004;42(I): I-8.

29. Kimbally-Kaky G, Makoumbou P, Nzingoula S. (Acute rheumatic fever among children in the Republic of Congo: report of 56 cases.) Dakar Med. 2002; 47(1):57-59.

30. Jaiyesimi F, Antia AU. Childhood rheumatic heart disease in Nigeria. Trop Geogr Med. 1981;33(1):8-13.

31. Sani MU, Karaye KM, Borodo MM. Prevalence and pattern of rheumatic heart disease in the Nigerian savannah: an echocardiographic study. Cardiovascular journal of Africa. 2007; 18(5):295-299.

32. Louw JW, Kinsley RH, Dion RA, et al. Emergency heart valve replacement: an analysis of 170 patients. Ann Thorac Surg. 1980;29(5):415-422.

33. Marcus RH, Sareli P, Pocock WA, et al. Functional anatomy of severe mitral regurgitation in active rheumatic carditis. Am J Cardiol. 1989;63(9):577-584.

34. Forman R, Beck W, Barnard CN. Results after mitral valve replacement with cloth-covered Starr-Edwards prostheses (models 6300, 6310/6320, and 6400). Br Heart J. 1978;40(6):612-616.

35. Koegelenberg CF, Doubell AF, Orth $\mathrm{H}$, et al. Infective endocarditis in the Western Cape Province of South Africa: a three-year prospective study. Qjm. 2003;96(3): 217-225.

36. Bennis A, Zahraoui M, Azzouzi L, et al. (Bacterial endocarditis in Morocco.) Ann Cardiol Angeiol (Paris). 1995;44(7):339-344.

37. Rush RW, Verjans M, Spracklen FH. Incidence of heart disease in pregnancy. A study done at Peninsula Maternity Services hospitals. S Afr Med J. 1979; 55(20):808-810.

38. Abengowe CU. Cardiovascular disease in Northern Nigeria. Trop Geogr Med. 1979;31 (4):553-560.

39. Schoon MG, Bam RH, Wolmarans L. Cardiac disease during pregnancy - a Free State perspective on maternal morbidity and mortality. S Afr Med J. 1997;87 Suppl I:C19-22.

40. Naidoo DP, Desai DK, Moodley J. Maternal deaths due to pre-existing cardiac disease. Cardiovasc J S Afr. 2002; 13(1): 17-20.

41. Anonymous. A review of maternal deaths in South Africa during 1998. National Committee on Confidential Enquiries into Maternal Deaths. S Afr Med J. 2000;90(4):367-373.

42. Nqayana T, Moodley J, Naidoo DP. Cardiac disease in pregnancy. Cardiovascular journal of Africa. 2008; 19(3): | 45- I5।. 
43. WorldHealthOrganisation. The current evidence for the burden of group A streptococcal diseases. http://www.who.int/child-adolescent-health/publications/ CHILD_HEALTH/DP/Topic_2/paper_l.htm.

44. Kechrid A, Kharrat $H$, Bousnina S, et al. Acute rheumatic fever in Tunisia. Serotypes of group A streptococci associated with rheumatic fever. Adv Exp Med Biol. 1997;418:121-123.

45. Tibazarwa KB, Volmink JA, Mayosi BM. Incidence of acute rheumatic fever in the world: a systematic review of population-based studies. Heart. 2008; 94(12): 1534-1540.

46. Strasser T, Dondog N, El Kholy A, et al. The community control of rheumatic fever and rheumatic heart disease: report of a WHO international cooperative project. Bulletin of the World Health Organisation. 1981;59(2):285-294.

47. Maharaj B, Dyer RB, Leary WP, et al. Screening for rheumatic heart disease amongst black school children in Inanda, South Africa. J Trop Pediatr. 1987; 33(1):60-61.

48. Oli K, Porteous J. Prevalence of rheumatic heart disease among school children in Addis Ababa. East Afr Med J. 1999;76(I I):60 I-605

49. Oli K, Porteous J. Prevalence of rheumatic heart disease among school children in Addis Ababa. East African Medical Journal. 1999;76(I I):60 I-605.

50. Folger GM, Jr., Hajar R, Robida A, et al. Occurrence of valvar heart disease in acute rheumatic fever without evident carditis: colour-flow Doppler identification. Br Heart J. 1992;67(6):434-438.

51. Abernethy M, Bass N, Sharpe N, et al. Doppler echocardiography and the early diagnosis of carditis in acute rheumatic fever. Aust N Z J Med. 1994; 24(5):530-535.

52. Veasy LG, Tani LY, Hill HR. Persistence of acute rheumatic fever in the intermountain area of the United States.[see comment]. Journal of Pediatrics. 1994;124(1):9-16

53. Figueroa FE, Fernandez MS, Valdes $\mathrm{P}$, et al Prospective comparison of clinical and echocardiographic diagnosis of rheumatic carditis: long term follow up of patients with subclinical disease. Heart. 200 I;85(4):407-4I 0.

54. Marijon E, Ou P, Celermajer DS, et al. Echocardiographic screening for rheumatic heart disease. Bull World Health Organ. 2008;86(2):84

55. MBewu AD. Welcome address: Rheumatic heart disease is a neglected disease of poverty requiring a multisectoral approach for control and eradication. S Afr Med J. 2006:96(3 Pt 2):231-232.

56. Robertson KA, Volmink JA, Mayosi BM. Towards a uniform plan for the contro of rheumatic fever and rheumatic heart disease in Africa--the Awareness Surveillance Advocacy Prevention (A.S.A.P.) Programme. S Afr Med J. 2006; 96(3 Pt 2):241.

57. Robertson KA, Volmink JA, Mayosi BM. Lack of adherence to the national guidelines on the prevention of rheumatic fever. S Afr Med J. 2005;95(I):52-56

58. Bisno AL, Gerber MA, Gwaltney JM, Jr., et al. Infectious Diseases Society of A. Practice guidelines for the diagnosis and management of group A streptococcal pharyngitis. Infectious Diseases Society of America. Clinical Infectious Diseases. 2002;35(2):113-125

59. Mayosi BM. Protocols for antibiotic use in primary and secondary prevention of rheumatic fever. S Afr Med J. 2006;96(3 Pt 2):240.

60. Steinhoff MC, Abd el Khalek MK, Khallaf N, et al. Effectiveness of clinical guidelines for the presumptive treatment of streptococcal pharyngitis in Egyptian children. Lancet. 1997;350(9082):918-921.

61. Robertson KA, Volmink JA, Mayosi BM. Antibiotics for the primary prevention of acute rheumatic fever: a meta-analysis. BMC Cardiovasc Disord. 2005;5(I ): I I.
62. Commerford PJ. Valvular heart disease in South Africa in 2005. S Afr Med J. 2005;95(8):568, 570, 572-564.

63. Antunes MD. Prosthetic heart valve replacement. Choice of prosthesis in a young, underdeveloped population group. S Afr Med J. 1985;68(I 0):755-758.

64. Antunes MJ, Wessels A, Sadowski RG, et al. Medtronic Hall valve replacement in a third-world population group. A review of the performance of 1000 prostheses. JThorac Cardiovasc Surg. 1988;95(6):980-993.

65. Skoularigis J, Sinovich $\mathrm{V}$, Joubert $\mathrm{G}$, et al. Evaluation of the long-term results of mitral valve repair in 254 young patients with rheumatic mitral regurgitation. Circulation. 1994:90(5 Pt 2):II I 67- 174

66. Bernal JM, Miralles PJ. Cardiac surgery with cardiopulmonary bypass during pregnancy. Obstetrical \& gynecological survey. 1986;4 ( (1): |-6.

67. Naidoo DP, Moodley J. Management of the critically ill cardiac patient. Best practice \& research. 200 I; I 5(4):523-544

68. Ben Farhat M, Betbout F, Gamra $H$, et al Results of percutaneous doubleballoon mitral commissurotomy in one medical center in Tunisia. Am J Cardiol. 1995;76(17):1266-1270

69. Andreu JM, Fourcade L, Balandraud P, et al. (General surgery and closed mitra commissurotomy: when necessity makes the rules.) Med Trop (Mars). 1999;59(2): 157-160

70. Barlow JB, Bosman CK. Aneurysmal protrusion of the posterior leaflet of the mitral valve. An auscultatory-electrocardiographic syndrome. Am Heart J. 1966;71 (2): 166-178.

71. Schaff HV, Suri RM, Enriquez-Sarano M. Indications for surgery in degenerative mitral valve disease. Semin Thorac Cardiovasc Surg. 2007;19(2):97-102.

72. Nkomo VT, Gardin JM, Skelton TN, et al. Burden of valvular heart diseases: a population-based study. Lancet. 2006;368(9540): 1005- I0 I I.

73. Commerford PJ, Curcio A, Albanese M, et al. Aortic valve replacement in the elderly. S Afr Med J. 1981;59(27):975-976

74. Sliwa K, Wilkinson D, Hansen C, et al. Spectrum of heart disease and risk factors in a black urban population in South Africa (the Heart of Soweto Study): a cohort study. Lancet. 2008;37I (9616):915-922

75. Robertson JH, Jackson JG. Cardiac aneurysms in Nigeria. J Pathol Bacteriol. 1960;80:101-109

76. Lurie AO. Left ventricular aneurysm in the African. Br Heart J. 1960;22:181-188.

77. Abrahams DG, Barton CJ, Cockshott WP, et al. Annular subvalvular left ventricular aneurysms. Q J Med. 1962;31:345-360.

78. Yacoub S, Kotit S, Mocumbi AO, et al. Neglected diseases in cardiology: a cal for urgent action. Nature clinical practice. 2008;5(4): I76- 177.

79. Mocumbi AO, Ferreira MB, Sidi D, et al. A population study of endomyocardial fibrosis in a rural area of Mozambique. $N$ Engl J Med. 2008; 359( 1$): 43-49$. 